Kocaeli Journal of Science and Engineering

\title{
Synthesis and Antioxidant Activities of Novel Naphthalimide Derivatives
}

\author{
Ufuk YILDIZ ${ }^{1, *}$ \\ ${ }^{1}$ Department of Chemistry, Zonguldak Bülent Ecevit University, Zonguldak, 67100, Turkey, ORCID: 0000-0002-0419-0011
}

Article Info

Research paper

Received : October 25,2020

Accepted : February 11, 2021

\section{Abstract}

In this study, synthesis and characterization of naphthalimide derivatives containing both amide and urea groups were performed and their antioxidant activities were determined. 4- $\boldsymbol{R}-1$ 8-naphthalic anhydride $\left(\boldsymbol{R}=-\mathrm{H},-\mathrm{NO}_{2}\right.$ or $\left.-\mathrm{NH}_{2}\right)$ with different functional groups has been chosen as the precursor and reacted with 5,6-diamino- $1 H$-benzo[ $d]$ imidazol-2(3H)-one to synthesize the targeted naphthalimide derivatives. ESI-MS and ${ }^{1} \mathrm{H}-\mathrm{NMR}$ techniques have been used to characterize the molecules. Antioxidant activities of compounds have been determined by DPPH and peroxide radical scavenging methods.
Keywords
Antioxidant
DPPH
Naphthalimide
Peroxide

\section{Introduction}

Antioxidants are molecules that can inhibit the oxidation of other molecules after the release of free radicals and prevent what is left [1]. Designing and developing compounds that can exhibit antioxidant activity is a very interesting field of study, as such compounds can help prevent many diseases such as stroke, diabetes, and many types of cancer by relieving oxidative stress $[2,3]$. Many types of natural compounds and different vitamins obtained from plants are used extensively in many industries such as food and cosmetics. Therefore, there is considerable scientific interest in discovering effective synthetic antioxidants.

Amide derivatives are an important chemical group displaying many biological activities [4-6]. For example, anilides are widely used in medicine, pharmacy, biology and other related fields due to their biological activities such as anti-bacterial, anti-fungal, anti-infectious, and anesthetic. Various anilides have also found a broad of applicability as bioactive species (antimicrobial, antioxidant, and antatherosclerotic agents) [7]. At the same time, synthetic amide derivatives can show strong antioxidant activity $[7,8]$.

Urea and thiourea are important functional groups in many natural products and drug intermediates. Urea and thiourea derivatives have many promising biological activities such as herbicide, antimicrobial, antioxidant, antiviral, anti-HIV and antitumor activity [9-13]. It is known that molecules with urea functional groups show enzyme inhibition and promising antioxidant activity [14, $15]$.

In this study, it is aimed to synthesize the compounds which could have high antioxidant activity due to including both urea and amide functional group (Figure 1). Thus, naphthalimide derivatives with different R-groups have been synthesized and their antioxidant activities have been examined.

\footnotetext{
${ }^{*}$ Corresponding Author: ufukyildiz@beun.edu.tr
} 

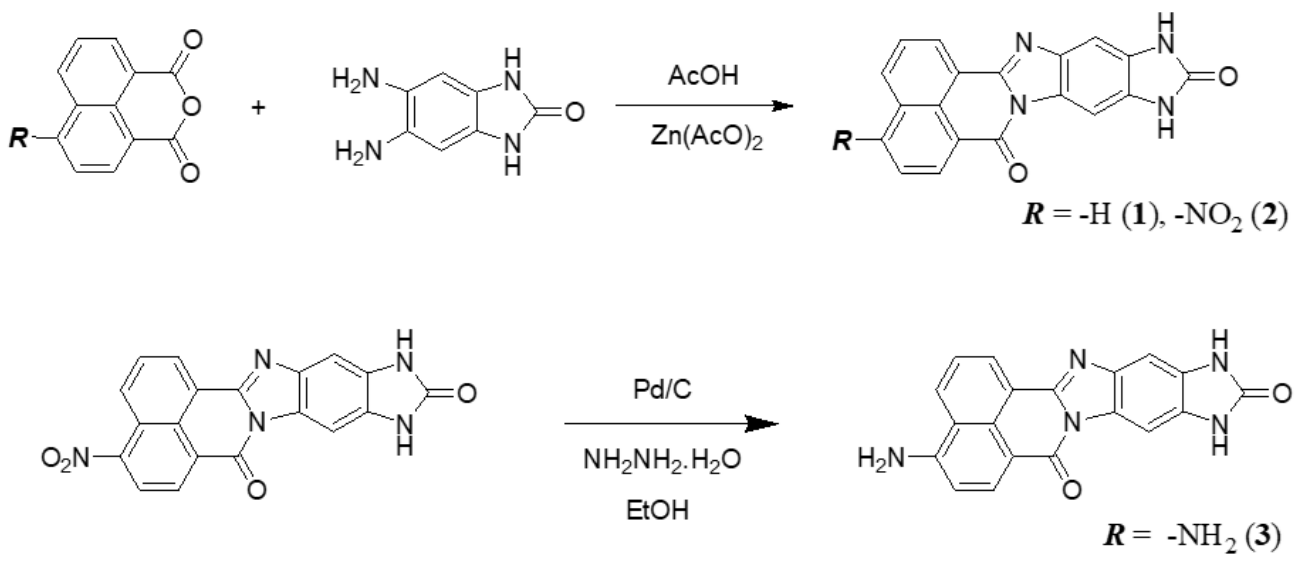

Figure 1. General synthesis procedure for compounds.

\section{Materials and Methods}

\subsection{Chemicals and Instruments}

All chemicals used were of analytical grade and obtained from Sigma-Aldrich unless otherwise stated. UVVis absorption measurements were carried out using Varian Cary 100 spectrophotometer device. Proton Nuclear Magnetic Resonance Spectroscopy ( ${ }^{1} \mathrm{H}$ NMR) was measured on a Bruker Ultra Shield Plus spectrometer, with chemical shifts reported as parts per million (in DMSO$\mathrm{d}_{6} / \mathrm{CDCl}_{3}, \mathrm{TMS}$ as an internal standard).

\subsection{Synthesis of Compounds}

\subsubsection{Synthesis of 1}

1 mmol (198 mg) 1,8-naphthalic anhydride was dissolved in $30 \mathrm{ml}$ of acetic acid and $1 \mathrm{mmol}(164 \mathrm{mg}) 5,6$ diamino-1H-benzo $[d]$ imidazol-2 $(3 H)$-one was added to the balloon. After adding 1 equivalent of zinc acetate to the mixture, it was boiled at $130^{\circ} \mathrm{C}$ under reflux overnight. After the reaction was completed, the balloon was then taken over the heater and cooled to room temperature. Precipitation was formed by the addition of crushed ice. The precipitate formed was filtered under vacuum and washed sequentially with acetone, ethanol and ether. The commercially available compound obtained was characterized by electrospray ionization mass spectrometry (ESI-MS) and ${ }^{1} \mathrm{H}-\mathrm{NMR}$ techniques. Yield: 68\%. M.p.: $165{ }^{\circ} \mathrm{C}$. ESI-MS: $\mathrm{m} / \mathrm{z}=327.0[\mathrm{M}+\mathrm{H}]$ (Fig. A.1). ${ }^{1} \mathrm{HNMR}$ (600 MHz, DMSO-d $6 \delta$, ppm): 10.87 (s, 1H, NH), 10.80 (s, $1 \mathrm{H}, \mathrm{NH}), 8.62(\mathrm{~m}, 2 \mathrm{H}, \mathrm{CH}), 8.46(\mathrm{~d}, 1 \mathrm{H}, \mathrm{CH}), 8.27(\mathrm{~d}, 1 \mathrm{H}$, $\mathrm{CH}), 7.94(\mathrm{~s}, 1 \mathrm{H}, \mathrm{CH}), 7.94(\mathrm{~s}, 1 \mathrm{H}, \mathrm{CH}), 7.87(\mathrm{t}, 1 \mathrm{H}, \mathrm{CH})$, 7.84 (t, 1H, CH), (Fig. A.2).

\subsubsection{Synthesis of 2}

Synthesis of compound 2 was achieved by the same way, using $1 \mathrm{mmol}$ (243 mg) 4-nitro-1,8-naphthalic anhydride. Yield: $59 \%$. M.p.: $173{ }^{\circ} \mathrm{C}$. ESI-MS: $\mathrm{m} / \mathrm{z}=$ $372.0[\mathrm{M}+\mathrm{H}]$ (Fig. A.3). ${ }^{1} \mathrm{HNMR}\left(600 \mathrm{MHz}, \mathrm{DMSO}^{-\mathrm{d}_{6}} \delta\right.$, ppm): 10.84 (s, 1H, NH), 8.80+8.60 (d, 2H, CH), 8.75 (s, $1 \mathrm{H}, \mathrm{CH}), 8.05+8.01(\mathrm{t}, 2 \mathrm{H}, \mathrm{CH}), 7.89(\mathrm{~s}, 1 \mathrm{H}, \mathrm{CH})$, 7.44+7.37 (m, 2H, CH), 7.28 (s, 1H, CH) (Fig. A.4).

\subsubsection{Synthesis of 3}

Compound 2 was used as a reagent in the reaction. $110 \mathrm{mg}$ of 2 was taken into the flask and dissolved in 50 $\mathrm{ml}$ of ethanol by boiling. $0.5 \mathrm{~g}$ of $\mathrm{Pd} / \mathrm{C}$ and excess of hydrazine hydrate were added. The mixture was boiled under reflux for 6 hours, then filtered while hot and the $\mathrm{Pd} / \mathrm{C}$ was removed. The remaining solution was cooled to room temperature and ether was added. The precipitate formed was filtered and washed sequentially with cold acetone and ether. The product was characterized by mass and NMR techniques. Yield: $52 \%$. M.p.: $178^{\circ} \mathrm{C}$. ESI-MS: $\mathrm{m} / \mathrm{z}=341.7[\mathrm{M}+\mathrm{H}]$ (Fig. A.5). ${ }^{1} \mathrm{HNMR}(600 \mathrm{MHz}$, DMSO-d $_{6} \delta$, ppm): $10.88(\mathrm{~s}, 1 \mathrm{H}, \mathrm{NH}), 10.81(\mathrm{~s}, 1 \mathrm{H}, \mathrm{NH})$, $8.75+8.72+8.62(\mathrm{~m}, 2 \mathrm{H}, \mathrm{CH}), 8.50+8.48+8.42(\mathrm{~m}, 2 \mathrm{H}$, $\mathrm{CH}), 8.27+8.21+8.05+8.01(\mathrm{~m}, 3 \mathrm{H}, \mathrm{CH}), 7.95(\mathrm{~s}, 1 \mathrm{H}, \mathrm{CH})$, 7.31 (s, 1H, CH) (Fig. A.6).

\subsection{Antioxidant Assays}

\subsubsection{1,1-diphenyl-2-picrylhydrazyl (DPPH)} radical scavenging activity

DPPH method previously reported in the literature was modified and applied [16]. DPPH radical absorbs at $517 \mathrm{~nm}$ wavelength. Stabilized DPPH was determined by following the absorbance at this wavelength. In the study, solutions of DPPH $(0.5 \mathrm{mM})$ and compounds $(0,10,20$, 
40, 80 and $100 \mu \mathrm{M}$ ) were prepared by dissolving in ethanol. $1.8 \mathrm{~mL}$ of DPPH solution was well mixed with 0.2 $\mathrm{mL}$ of a solution of the compound. Absorbance at $517 \mathrm{~nm}$ of the resulting solution (DPPH + samples) was recorded after incubation for half an hour in dark. The abilities of compounds to stabilize DPPH radical was examined using the formula;

$\mathrm{DPPH} \%=\left(\mathrm{A}_{\mathrm{c}}-\mathrm{A}_{\mathrm{s}}\right) / \mathrm{A}_{\mathrm{c}} \mathrm{x} 100$

where $A_{c}$ is absorbance of control and $A_{s}$ is absorbance of sample mixture at $517 \mathrm{~nm}$. The required concentration of compounds to stabilize the half of the DPPH radical $\left(\mathrm{IC}_{50}\right)$ was calculated.

\subsubsection{Hydrogen Peroxide Scavenging Activity}

The $\mathrm{H}_{2} \mathrm{O}_{2}$ scavenging abilities of the compounds were determined according to the literature [17]. $0.6 \mathrm{~mL}$ of 40 $\mathrm{mM} \mathrm{H} \mathrm{O}_{2}$ solution ( $\mathrm{pH}$ 7.4) was well mixed with the 100 , 250 , and $500 \mu \mathrm{g} / \mathrm{mL}$ of the samples. The absorbance of prepared mixtures at $230 \mathrm{~nm}$ were recorded after incubation for $10 \mathrm{~min}$. The abilities of compounds to scavenge the peroxide radicals was examined using the formula;

$\mathrm{H}_{2} \mathrm{O}_{2} \%=\left(\mathrm{A}_{\mathrm{c}}-\mathrm{A}_{\mathrm{s}}\right) / \mathrm{A}_{\mathrm{c}} \times 100$

where $A_{c}$ is absorbance of control and $A_{s}$ is absorbance of sample mixture at $230 \mathrm{~nm}$.

\section{Results and Discussion}

\subsection{Synthesis of the compounds}

${ }^{1} \mathrm{H}$ NMR spectroscopy and ESI-MS spectroscopy techniques were used to analyse the structure of the compounds. The ESI-MS result for compound 1 (Figure S1) $(327.0(\mathrm{M}+\mathrm{H}))$ directly matches with the calculated molecular weight $(356.3 \mathrm{~g} / \mathrm{mol})$. When the ${ }^{1} \mathrm{H}$ NMR spectrum of $\mathbf{1}$ is examined, number of protons derived from ${ }^{1} \mathrm{H}$ NMR spectrum is compatible with the targeted molecule. The chemical shifts of the protons numbered 7 and 8 (Fig.S2) were observed at different ppm values due to the fact that the proton number 7 is attached to a partially positive carbon as a result of conjugation. Likewise, protons attached to nitrogen atoms have very close chemical shift values to each other but at separate ppm values due to differences in charge distribution. When the structure is examined completely, the chemical shift of all protons is in the expected region and confirms the structure.

When the mass distribution of compound $\mathbf{2}$ is examined, the high peak appeared at $\mathrm{m} / \mathrm{z}=372$ directly confirms the structure as the $\mathrm{M}+\mathrm{H}$ molecular ion peak. The ${ }^{1} \mathrm{H}$ NMR spectrum of $\mathbf{2}$ shows that the compound was synthesized as two different isomers as expected Fig. A.7). Number of integrated protons directly matches with the structure of the targeted molecule. Since the carbon atom to which the proton number 4 is attached is adjacent to the carbon attached to the electron withdrawing nitro group, the chemical shift value has increased up to $8.8 \mathrm{ppm}$. Since TFA was used together with DMSO as a solvent in the spectrum, one of the nitrogen protons 8 and 9 could not be observed. The ${ }^{1} \mathrm{H}$ NMR spectrum of the compound suggests that $\mathbf{2}$ has been synthesized as its two isomers mixture with the ratio of $56 \%$ and $44 \%$, while the triplets of the proton 2 gave twin signals at 8.05 and $8.00 \mathrm{ppm}$.

ESI-MS spectra of $\mathbf{3}$ indicated that the molecular weight of the compound is $341.3 \mathrm{~g} / \mathrm{mol}$ as supposed. The ${ }^{1} \mathrm{H}$ NMR spectrum of $\mathbf{3}$ is similar to the spectrum of $\mathbf{2}$. The $1 \mathrm{H}$ NMR spectrum of the compound suggests that $\mathbf{3}$ has been synthesized as its two isomers as a continuation of 2 with the ratio of $56 \%$ and $44 \%$

\subsection{Antioxidant Activities}

Elimination of reactive species is an issue that is taken into consideration, as it causes various health problems by damaging the biochemical molecules in the organism. The task of the compounds that provide protection against cancer by showing antioxidant activity is to stabilize free radicals. This process occurs when compounds donate either a single electron or hydrogen atom to free radicals [18]. In this study, DPPH and $\mathrm{H}_{2} \mathrm{O}_{2}$ methods were used, which give results much faster than other methods. All the newly synthesized compounds showed potent to moderate radical scavenging activities at all concentrations.

DPPH radical scavenging activity of compounds is related to their tendency to donate hydrogen or single electron [19]. The results of percentage inhibition of the DPPH radical by synthesized compounds and standard antioxidant Vit $\mathrm{C}$ with different concentrations were represented in Figure 2. The $\mathrm{IC}_{50}$ values calculated by using graph were illustrated in Table 1. 
Table 1. $\mathrm{IC}_{50}$ and total scavenging percentages of compounds.

\begin{tabular}{|c|c|c|c|c|}
\hline & \multicolumn{2}{|c|}{ DPPH } & \multicolumn{2}{c|}{$\mathrm{H}_{2} \mathrm{O}_{2}$} \\
\hline Compound & $\mathrm{IC}_{50}(\mu \mathrm{M})$ & Tot. Scavenging $\%$ & $\mathrm{IC}_{50}(\mu \mathrm{g} / \mathrm{mL})$ & Tot. Scavenging $\%$ \\
\hline 1 & 35.1 & 73.9 & 550.2 & 48.7 \\
\hline 2 & 18.7 & 74.9 & 487.2 & 51.6 \\
\hline 3 & 12.3 & 82.6 & 251.1 & 66.7 \\
\hline Vit C & 39.2 & 88 & 409.5 & 58 \\
\hline
\end{tabular}

$\mathrm{IC}_{50}$ value of $\mathrm{DPPH}$ for Vit $\mathrm{C}$ used as standard antioxidant was calculated as $39.2 \mu \mathrm{M}$ while $\mathrm{IC}_{50}$ value for all compounds were greater than Vit $\mathrm{C}$. The $\mathrm{NH}_{2}$ functional group in compound $\mathbf{3}$ increased antioxidant activity with $12.3 \mu \mathrm{M}$ due $\mathrm{IC}_{50}$ value due to increasing the possibility of $\mathrm{H}$-donating.

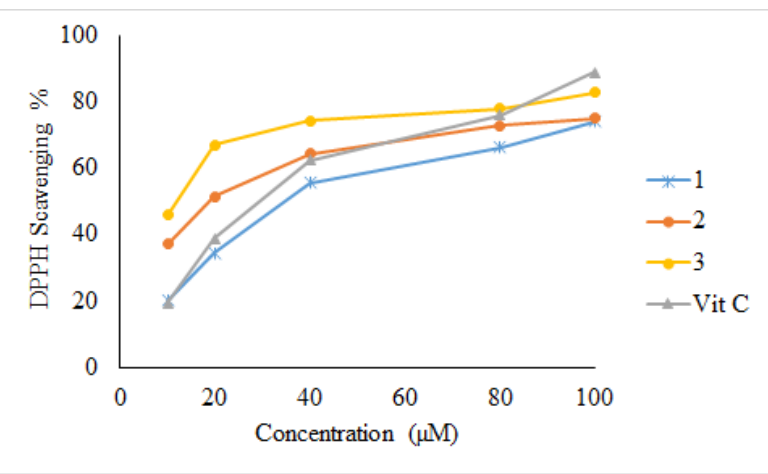

Figure 2. Antioxidant activities of compounds by DPPH method.

Comparative DPPH scavenging percentages of compounds for different concentrations are shown in figure 3. These results indicated that total scavenging activity of compounds were lower than Vit C.

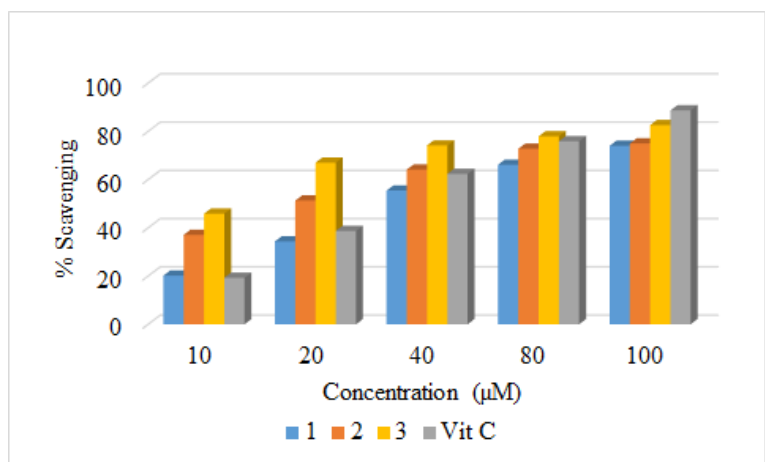

Figure 3. Percentage inhibition of DPPH scavenging activity of synthesized compounds in comparison to Vit C.

Synthesized compounds 1-3 were screened for in vitro scavenging activity utilizing hydrogen peroxide. These tested compounds showed moderate hydrogen peroxide scavenging activity.

The ability compound $\mathbf{1}$ and 2 to scavenge hydrogen peroxide were lower than Vit $\mathrm{C}$ but compound 3 had a better $\mathrm{IC}_{50}$ with $251.1 \mu \mathrm{g} / \mathrm{mL}$ (Fig.4). Scavenging activities of compounds were dose-dependent and increased with concentration.

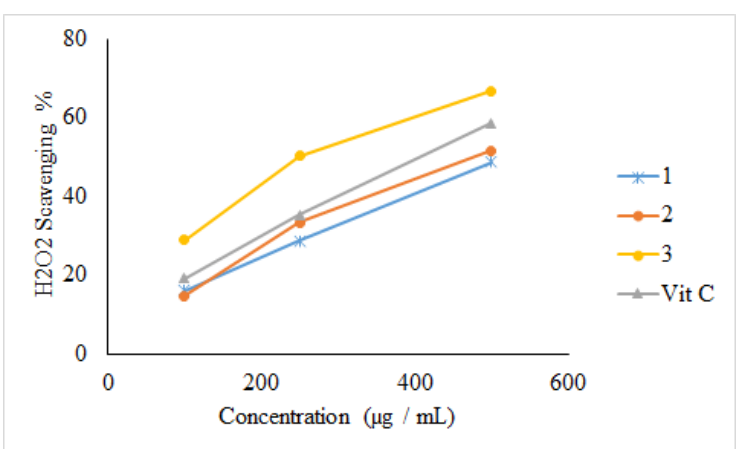

Figure 4. Antioxidant activities of compounds by $\mathrm{H}_{2} \mathrm{O}_{2}$ method.

Total hydrogen peroxide radical scavenging percentage of compounds at $500 \mu \mathrm{g} / \mathrm{mL}$ were 48.7 for $\mathbf{1}, 51.6$ for 2 and 66.7 for 3 (Fig.5). Similar to the DPPH method, compound 3 could scavenge $\mathrm{H}_{2} \mathrm{O}_{2}$ radicals as effective as well-known antioxidant Vit $\mathrm{C}$.

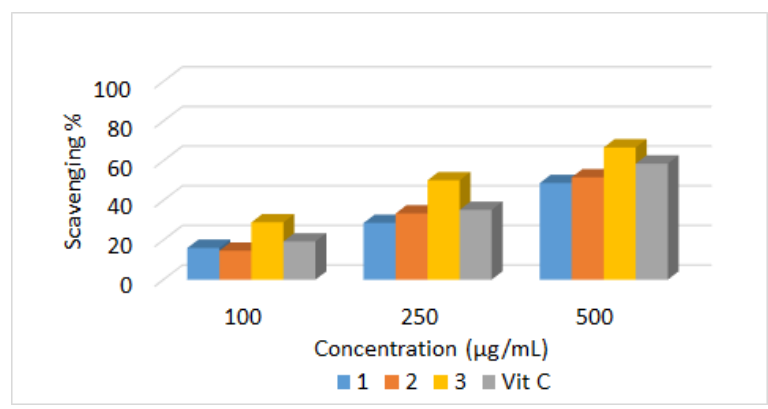

Figure 5. Percentage inhibition of hydrogen peroxide scavenging activity of synthesized compounds in comparison to Vit C.

\section{Conclusions}

As a result, the antioxidant activities of the newly synthesized naphthalimide derivatives were determined by 
DPPH and $\mathrm{H}_{2} \mathrm{O}_{2}$ methods. Adding functional group for single electron and $-\mathrm{H}$ donating just as nitro (compound 2) and amino (compound 3) prominently enhanced the antioxidant capacity. The availability of these new naphthalimide derivatives would facilitate further investigations of their applications in food and pharmaceutical industries.

\section{Declaration of Ethical Standards}

The author(s) of this article declare that the materials and methods used in this study do not require ethical committee permission and/or legal-special permission.

\section{Conflict of Interest}

The authors declare that they have no known competing financial interests or personal relationships that could have appeared to influence the work reported in this paper.

\section{Acknowledgements}

We are grateful for the support of Zonguldak Bulent Ecevit University with grant 2019-72118496-02.

\section{References}

[1] Cornelli U., 2009.Antioxidant use in nutraceuticals. Clinics in Dermatology 27(2), p. 175-194.

[2] Giugliano D., Ceriello A., and Paolisso G., 1995.Diabetes mellitus, hypertension, and cardiovascular disease: Which role for oxidative stress? Metabolism 44(3), p. 363-368.

[3] Reuter S., Gupta S.C., Chaturvedi M.M., and Aggarwal B.B., 2010.Oxidative stress, inflammation, and cancer: How are they linked? Free Radical Biology and Medicine 49(11), p. 1603-1616.

[4] Saeedi M., Goli F., Mahdavi M., Dehghan G., Faramarzi M.A., Foroumadi A., and Shafiee A., 2014. Synthesis and Biological Investigation of some Novel Sulfonamide and Amide Derivatives Containing Coumarin Moieties. Iran J Pharm Res 13(3), p. 881-92.

[5] Huczyński A., Janczak J., Stefańska J., Antoszczak M., and Brzezinski B., 2012.Synthesis and antimicrobial activity of amide derivatives of polyether antibioticsalinomycin. Bioorganic \& Medicinal Chemistry Letters 22(14), p. 4697-4702.
[6] Narasimhan B., Belsare D., Pharande D., Mourya V., and Dhake A., 2004.Esters, amides and substituted derivatives of cinnamic acid: synthesis, antimicrobial activity and QSAR investigations. Eur J Med Chem 39(10), p. 82734.

[7] Kamat J.P. and Devasagayam T.P., 1999.Nicotinamide (vitamin B3) as an effective antioxidant against oxidative damage in rat brain mitochondria. Redox report : communications in free radical research 4(4), p. 179-184.

[8] Malki F., Touati A., and Moulay S. Comparative Study of Antioxidant Activity of Some Amides. 2017.

[9] Yonova P.A. and Stoilkova G.M., 2004.Synthesis and biological activity of urea and thiourea derivatives from 2-aminoheterocyclic compounds. Journal of Plant Growth Regulation 23(4), p. 280291.

[10] Abdel-Rahman H.M. and Morsy M.A., 2007. Novel benzothiazolyl urea and thiourea derivatives with potential cytotoxic and antimicrobial activities. Journal of Enzyme Inhibition and Medicinal Chemistry 22(1), p. 5764.

[11] Shusheng Z., Tianrong Z., Kun C., Youfeng X., and Bo Y., 2008.Simple and efficient synthesis of novel glycosyl thiourea derivatives as potential antitumor agents. European Journal of Medicinal Chemistry 43(12), p. 2778-2783.

[12] Özgeriş B., Akbaba Y., Özdemir Ö., Türkez H., Göksu S., 2017. Synthesis and Anticancer Activity of Novel Ureas and Sulfamides Incorporating 1-Aminotetralins. Archives of Medical Research 48 (6), p. 513-519.

[13] Özgeriş B., 2021. Design, synthesis, characterization, and biological evaluation of nicotinoyl thioureas as antimicrobial and antioxidant agents. The Journal of Antibiotics. https://doi.org/10.1038/s41429-020-00399-7

[14] Aksu K., Özgeriş B., Taslimi P., Naderi A., Gülçin İ., and Göksu S., 2016.Antioxidant Activity, Acetylcholinesterase, and Carbonic Anhydrase Inhibitory Properties of Novel Ureas Derived from Phenethylamines. Archiv der Pharmazie 349(12), p. 944-954.

[15] Bhaskara Reddy M.V., Srinivasulu D., Peddanna K., Apparao C., and Ramesh P., 2015.Synthesis and Antioxidant Activity of New Thiazole Analogues Possessing Urea, Thiourea, and 
Selenourea Functionality. Synthetic Communications 45(22), p. 2592-2600.

[16] Özel A., Barut B., Demirbaş Ü., and Biyiklioglu Z., 2016.Investigation of DNA binding, DNA photocleavage, topoisomerase I inhibition and antioxidant activities of water soluble titanium(IV) phthalocyanine compounds. Journal of Photochemistry and Photobiology B: Biology 157, p. 32-38.

[17] Al-Amiery A.A., Al-Majedy Y.K., Kadhum A.A.H., and Mohamad A.B., 2015.Hydrogen
Peroxide Scavenging Activity of Novel Coumarins Synthesized Using Different Approaches. PLOS ONE 10(7), p. e0132175.

[18] Soare J.R., Dinis T.C.P., Cunha A.P., and Almeida L., 1997.Antioxidant Activities of Some Extracts of Thymus zygis. Free Radical Research 26(5), p. 469-478.

[19] Blois M.S., 1958.Antioxidant Determinations by the Use of a Stable Free Radical. Nature 181(4617), p. 1199-1200.

\section{Appendices}

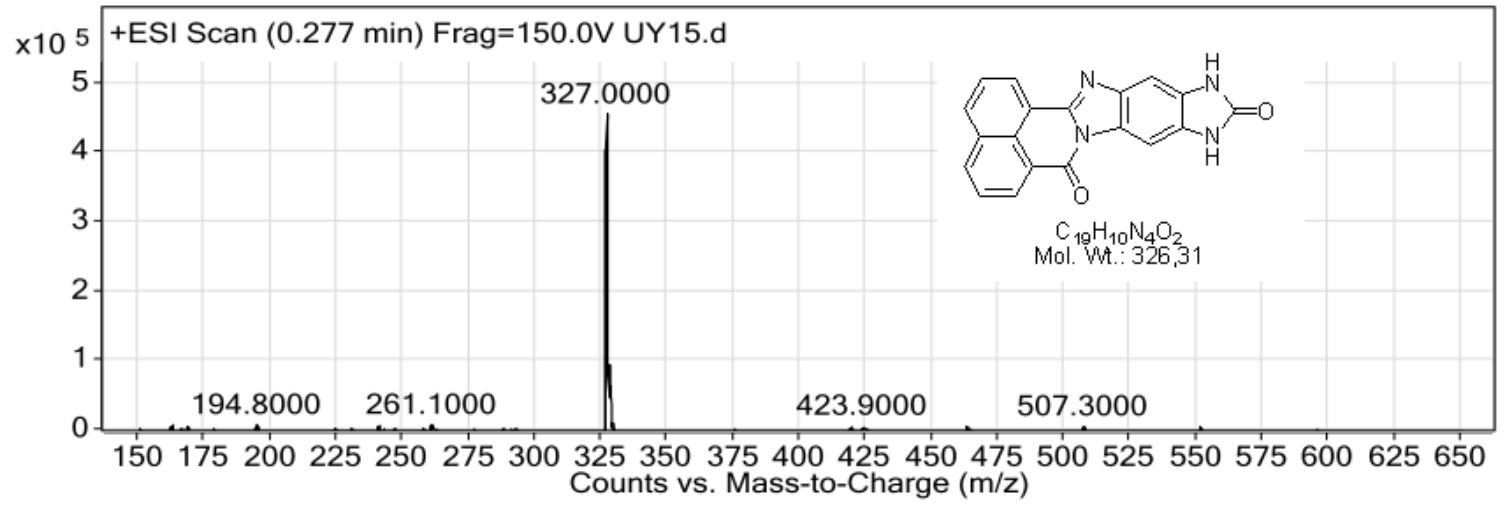

Figure A.1 ESI-MS spectrum for 1.

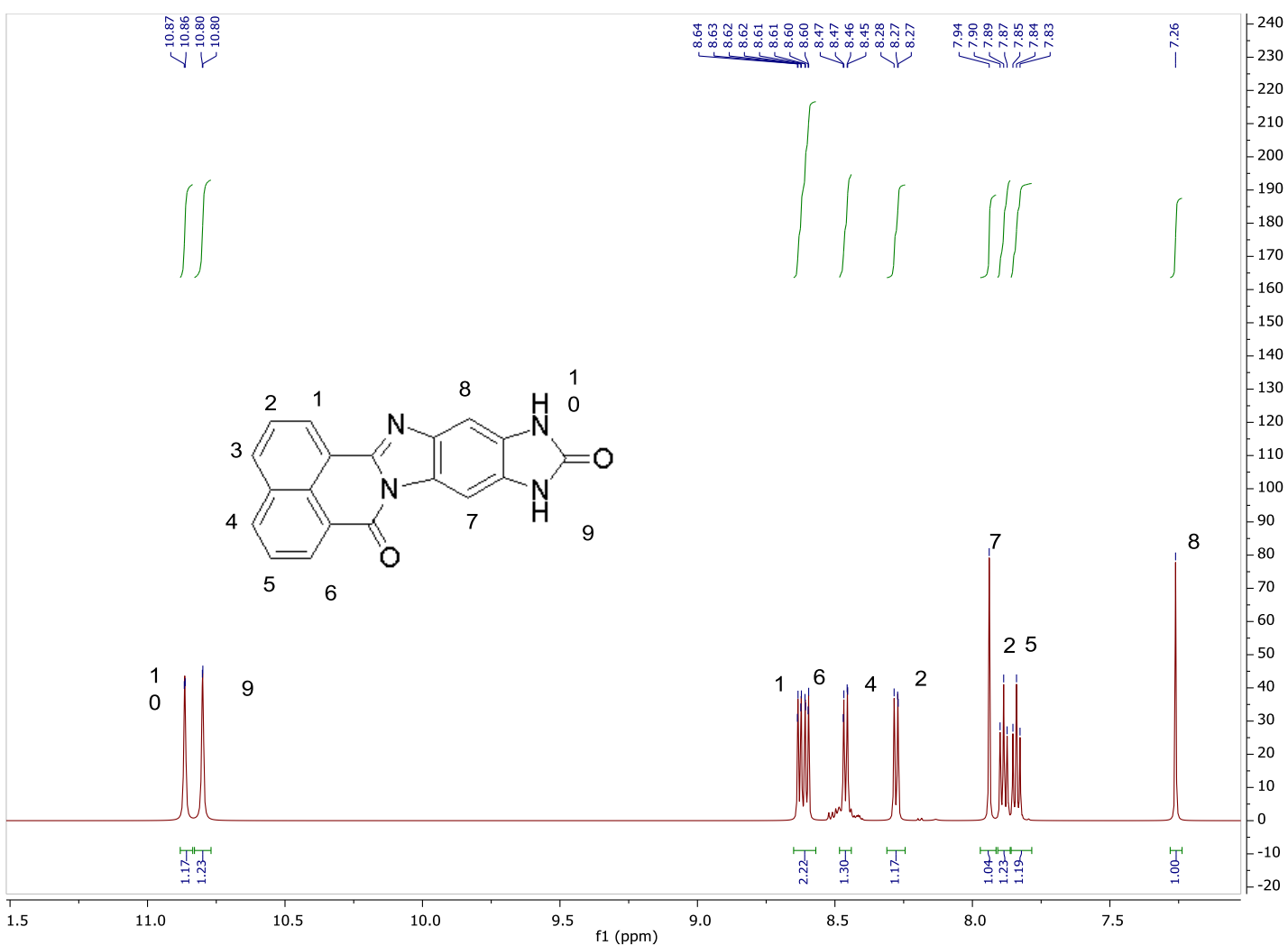

Figure A. $2{ }^{1} \mathrm{H}-\mathrm{NMR}$ spectrum for 1 . 


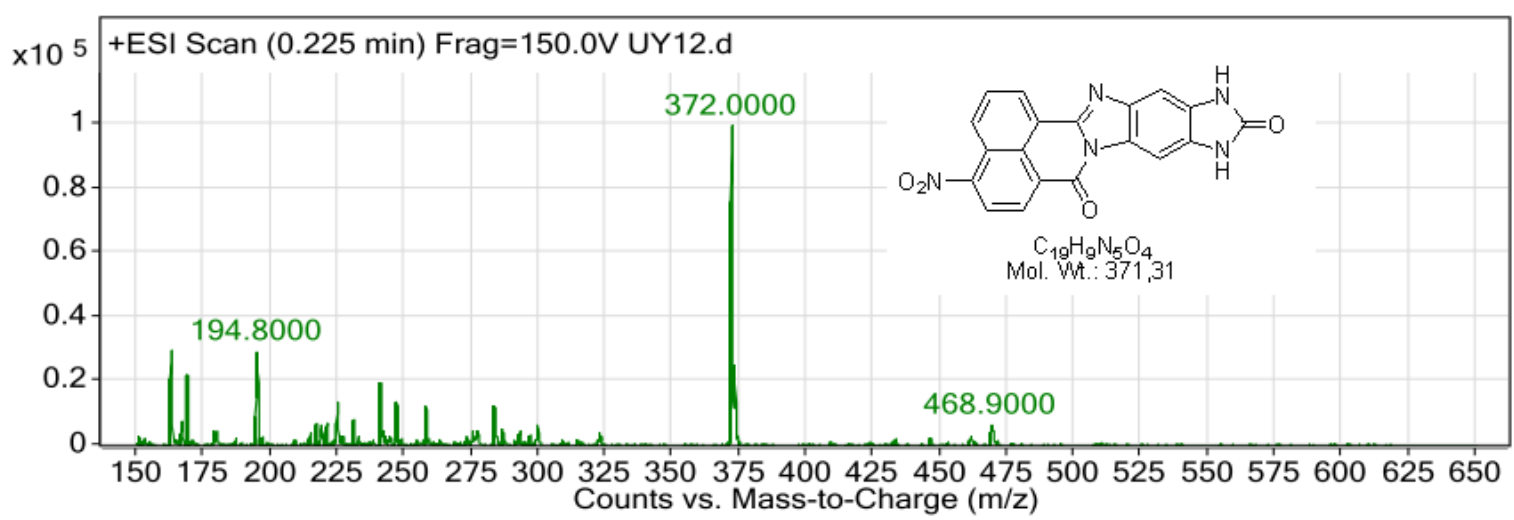

Figure A.3 ESI-MS spectrum for 2.

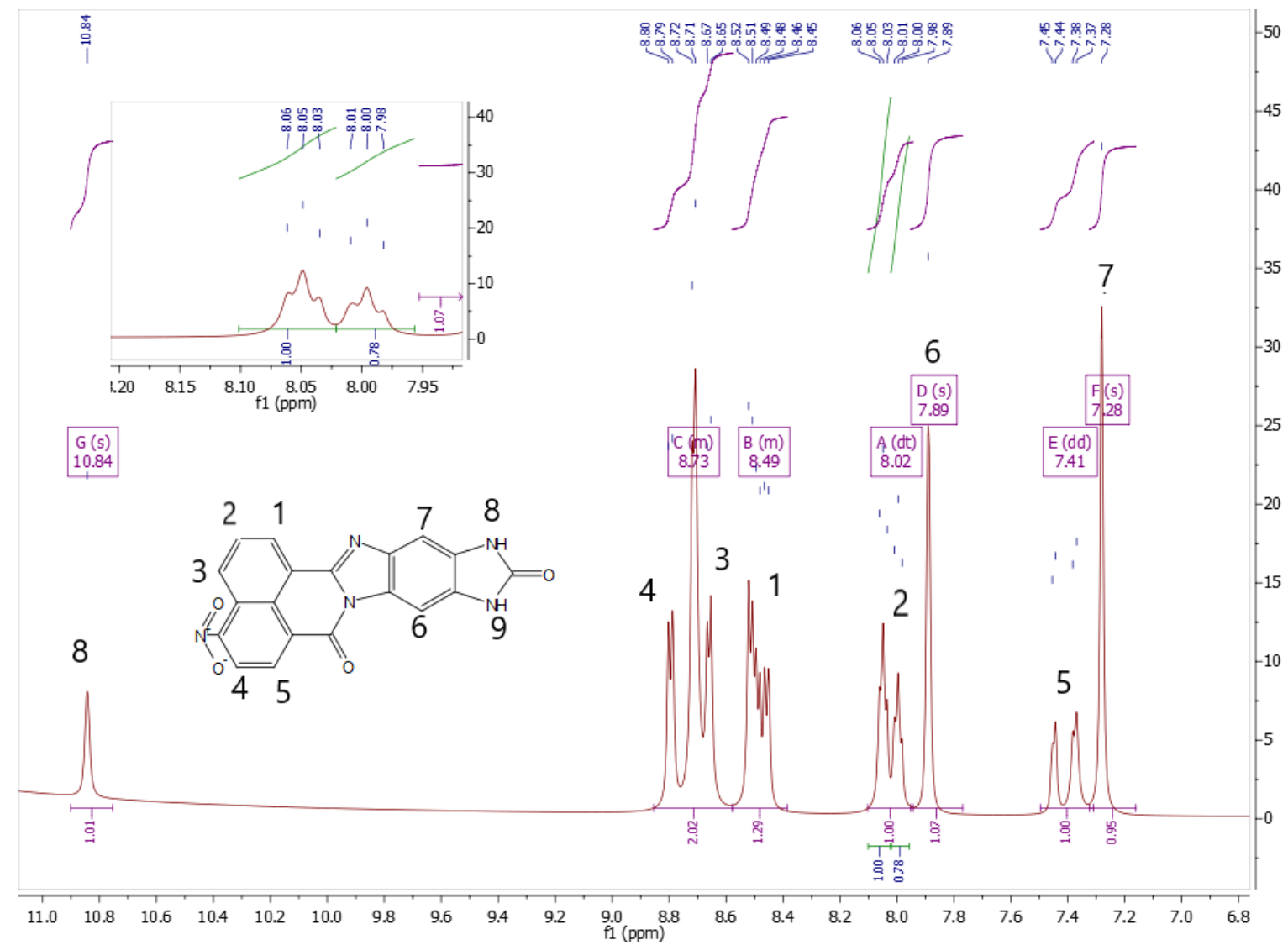

Figure A.4 ${ }^{1} \mathrm{H}-\mathrm{NMR}$ spectrum for 2 .

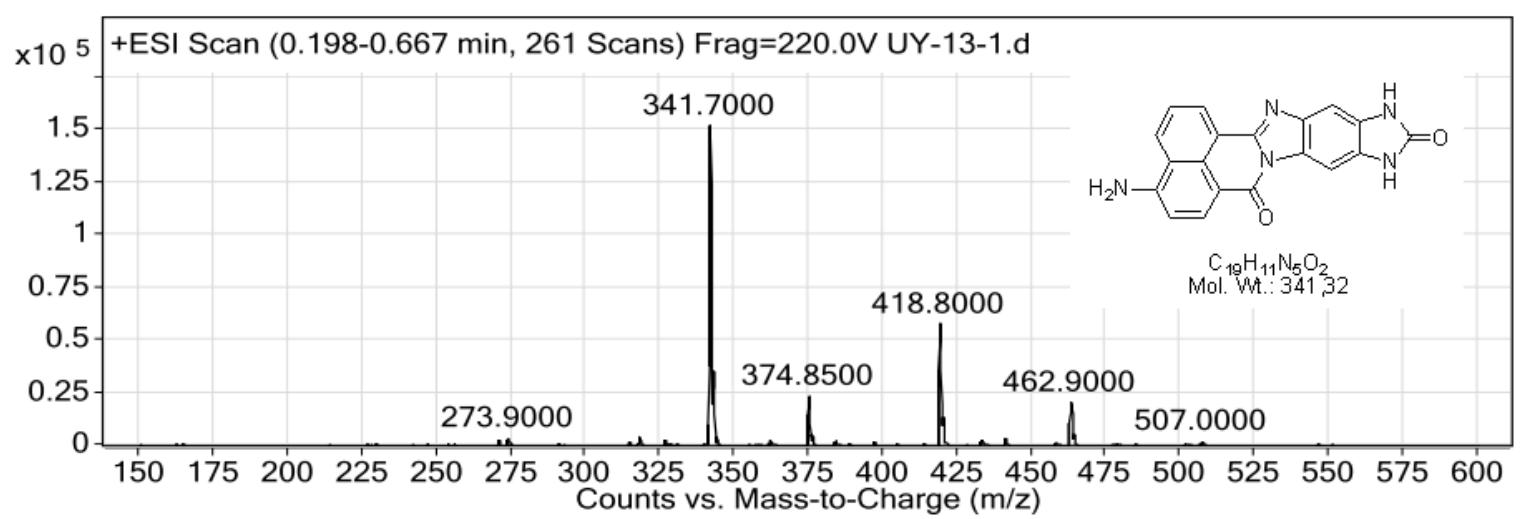

Figure A.5 ESI-MS spectrum for 3. 


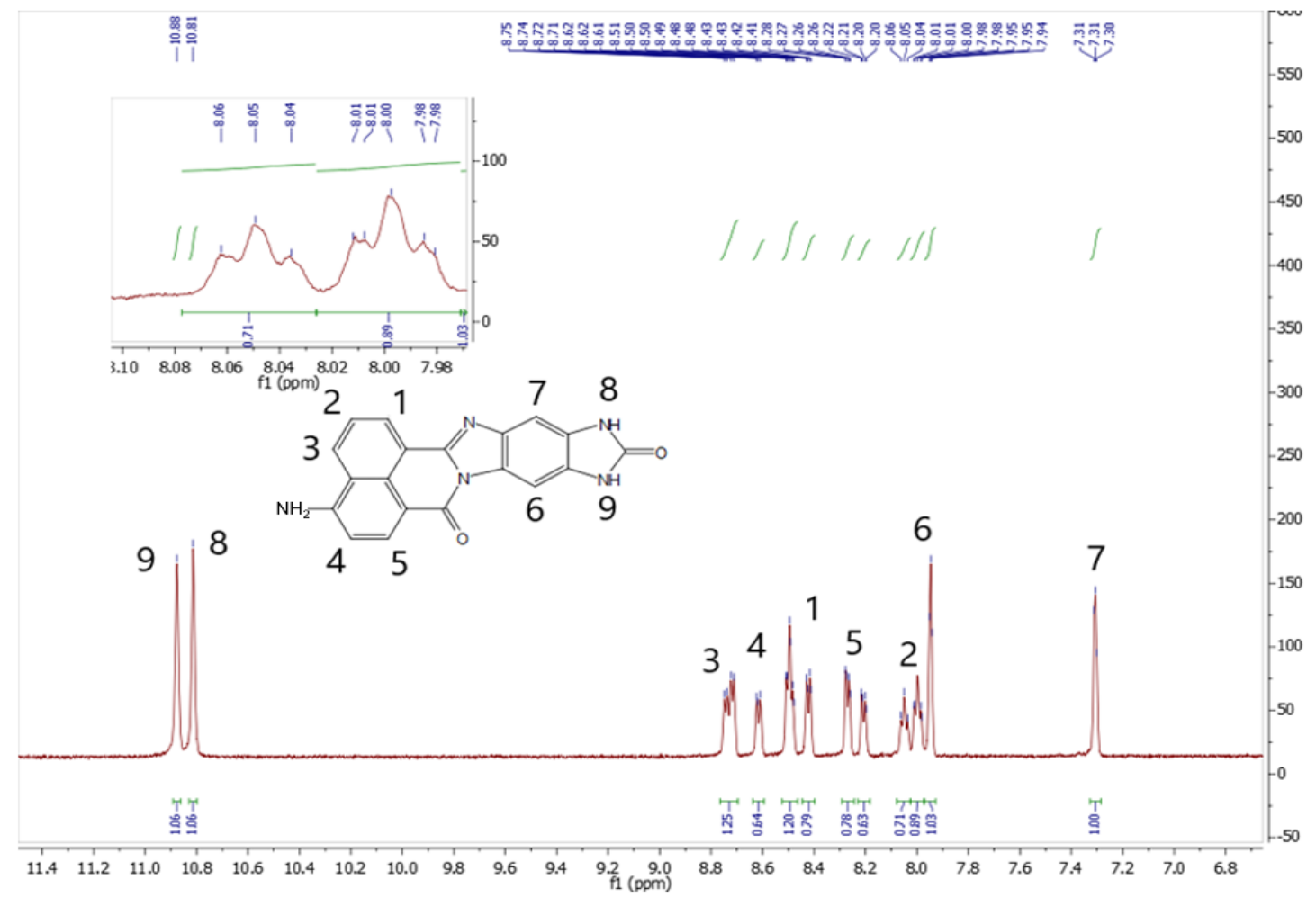

Figure A.6 ${ }^{1} \mathrm{H}-\mathrm{NMR}$ spectrum for $\mathbf{3}$<smiles>[R]c1ccc2c(=O)n3c4cc5[nH]c(=O)[nH]c5cc4nc3c3cccc1c23</smiles><smiles>[R]c1ccc2c3cccc4c(=O)n5c(nc6cc7[nH]c(=O)[nH]c7cc65)c=4c3c1-2</smiles>

Figure A.7 The structures of possible isomers. 